\title{
Can Mathematical Models of Body Heat Exchanges Accurately Predict Thermal Stress in Premature Neonates?
}

\author{
Stéphane Delanaud ${ }^{1, *}$, Fatima Chahin Yassin ${ }^{1}$, Estelle Durand ${ }^{1}$, Pierre Tourneux ${ }^{1,2}$ and \\ Jean-Pierre Libert ${ }^{1}$ \\ 1 PériTox (UMR_I 01 Unité Mixte INERIS), CURS, Présidence, Chemin du Thil, Université de Picardie Jules \\ Verne, F-80000 Amiens, France; fatima.yassine@u-picardie.fr (F.C.Y.); estelle.durand@u-picardie.fr (E.D.); \\ Tourneux.Pierre@chu-amiens.fr (P.T.); jean-pierre.libert@u-picardie.fr (J.-P.L.) \\ 2 Pediatric intensive care service, CHU Amiens-Picardie, F-80000 Amiens, France \\ * Correspondence: stephane.delanaud@u-picardie.fr; Tel.: +33-(03)-22827747
}

Received: 31 January 2019; Accepted: 6 April 2019; Published: 13 April 2019

check for updates

Featured Application: Assistance with care for low-birth- weight neonates, diagnosis of thermal stress, and the manufacture of closed incubators.

\begin{abstract}
Mathematical models of body heat exchanges can be used to define the thermal limits needed to protect premature neonates nursed in incubators against thermal stress-stress that can have potentially devastating impairments on neurological development and body growth. Predictive models can help caregivers to keep a neonate's body temperature within the normal range and to solve problems that arise during intensive care, such as the risk of hyperthermia during phototherapy, the risk of hypothermia during transport from one clinical centre to another, and the use of a plastic bag to reduce skin water loss and body dehydration. Here, we review the strengths and limitations of models used to predict the risk of thermal stress, with a focus on uncertainties in the algorithms governing heat transfers between the neonate's skin and the complicated thermal environment encountered in incubators. We describe attempts to reduce the large number of empirical assumptions and uncertainties in this field, and suggest ways of more accurately modelling optimal thermal conditions for neonates nursed in closed incubators.
\end{abstract}

Keywords: model; neonate; body heat exchange; nursing care; incubator; thermal management

\section{Introduction}

Optimizing a premature neonate's thermal environment is still a challenge in routine clinical care. There are several reasons why poorly effective thermoregulatory responses to thermal changes increase the risk of thermal stress in preterm infants. Firstly, the level of basal metabolism (when expressed per unit of skin surface area) is lower in preterm infants than in adults. Secondly, the sweat glands do not operate effectively in infants with a gestational age below 30 weeks [1]. Thirdly, there is evidence to suggest that immature neonates' peripheral vasomotor responses are impaired during the first few hours after birth [2,3]. Fourthly, the skin's high permeability increases evaporative heat losses. Lastly, body heat exchanges with the environment are larger in infants than in adults as a result of the high skin surface area/body volume ratio and the body segments' high degree of curvature.

Optimal thermal conditions are generally defined those resulting in a core body temperature of between 36.5 and $37.5^{\circ} \mathrm{C}$ [4]. Heat stress (corresponding to a core body temperature above $37.5^{\circ} \mathrm{C}$ ) can result from increased body heat storage caused by (i) over-insulation from excessive clothing, (ii) high environmental temperatures, (iii) fever and/or (iv) immature, inefficient thermoregulatory processes. 
Body overheating can also occur if a neonate is wrapped in a plastic bag at birth $[5,6]$; indeed, several researchers have called for further research into the effectiveness of this procedure $[5,7,8]$. When heat stroke (extreme body temperature $\geq 40{ }^{\circ} \mathrm{C}$ ) occurs, cell damage leads to coma, shock, convulsions, severe neurological impairments, kidney failure and haemorrhage [9].

The World Health Organization defines cold stress as a core body temperature of between 36.0 and $32.0^{\circ} \mathrm{C}$. When exposed to low ambient temperatures, the neonate reduces its peripheral blood flow and increases the metabolic heat production. This mechanism decreases the energy available for tissue synthesis and thus impairs body growth. The increase in the metabolic rate induces hypoglycaemia and blood acidosis through the release of lactic acid. Prolonged cold exposure is life-threatening. For example, Laptook et al. [5] reported that the odds ratios for late sepsis and death respectively increased by $11 \%$ and $28 \%$ for a $1{ }^{\circ} \mathrm{C}$ decrement in admission body temperature. In summary, the pathological effects of thermal stress in neonates are particularly devastating, and include severe impairments in neurological development and body growth.

Here, we review the strengths and limitations of models used to both predict the optimal thermoneutral incubator air temperature $\left(\mathrm{T}_{\text {inc }}\right)$ for nursed neonates and avoid the risk of thermal stress. Ideally, a model should incorporate all the variables related to body temperature regulation. However, given the complexities of the body's thermoregulatory system and the simplifications needed to describe the various heat transfers between the skin surface area and the environment, care providers do not yet trust these models to make accurate predictions.

\section{Why Are Mathematical Models of Value?}

Interest in using mathematical models of body heat exchanges is growing steadily, despite the fact that the complex equations describing these exchanges have to be simplified for successful implementation. This growth in interest is illustrated by the development of computer programs for determining the optimal thermal environment for low-birth-weight neonates in a closed incubator. The development of this type of quantitative model is also driven by the need to better understand how a neonate responds to extreme body overheating or cooling; for obvious ethical reasons, these situations cannot be studied directly.

In general, management of an incubator's thermal environment is based on the measurement of physiological variables. Environmental control is mainly focused on air temperature and thus does not take account of other relevant environmental parameters. The difference between peripheral skin temperatures (at the hand or foot) and central (abdominal) skin temperatures can also be used to assess heat stress because it disappears when the neonate is overheating. Hypothermia and hyperthermia can also be detected by measuring the internal (core) temperature, which is assumed to reflect changes in body heat storage. Although the rectal temperature remains the gold standard for measuring excessive body warming, the placement of a temperature probe in the rectum is not recommended in routine clinical practice because it is associated with a risk of rectal perforation especially in very small neonates [10]. However, few other measurement sites and monitoring devices have been studied. The tympanic temperature is thought to reflect the core body temperature, given its proximity to the hypothalamus (the coordinating centre for body temperature control) and its vascular supply. However, the ear drum can also be perforated by a temperature probe. The axillary temperature is a safe option but its accuracy is questionable; measurements can be influenced by the peripheral regional vasoconstriction that occurs in some cases of malignant hyperthermia (due to high levels of circulating catecholamines). As with the rectal temperature, measurement of the oesophageal temperature is not recommended in routine clinical practice. Moreover, these local temperatures do not correspond to the "core body temperature" - the erroneous use of the latter term in certain publications. Lenzi et al. [11] reported that in both humans and rabbits, thermoregulatory adjustments involve opposite regional temperature changes. Cross et al. [12] showed that in a thermoneutral environment, the rectal temperature was lower than the oesophageal and aural temperatures. Temperatures close to 
that of rectum can be found in the deep central organs but not elsewhere, and so it is better to express the risk of thermal stress in terms of body heat storage.

Hence, computer models are based on the maintenance of a balance between metabolic heat generation in the body $(\mathrm{M})$ and heat exchanges (by conduction, convection, evaporation and radiation) between the skin and the environment (Figure 1).

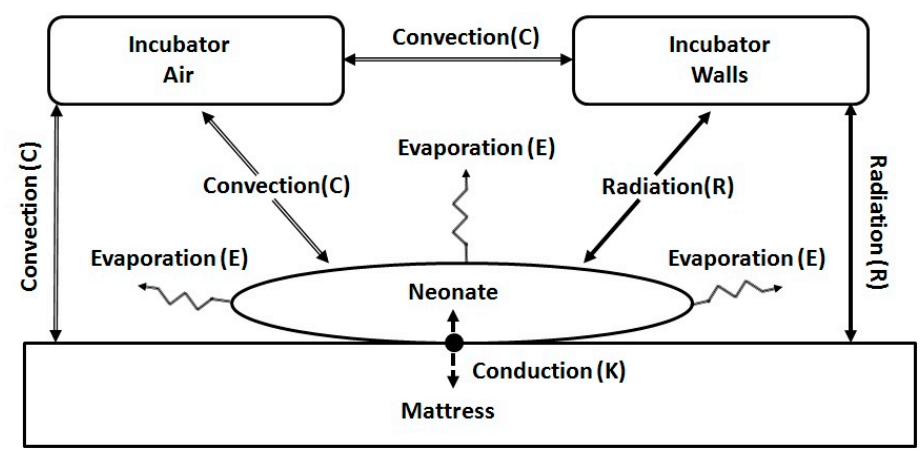

Figure 1. A simplified block diagram of the heat exchanges between the neonate's skin and the environment: $\mathrm{K}, \mathrm{C}, \mathrm{R}$ and $\mathrm{E}$ are respectively the conductive, convective, radiant and evaporative heat transfers.

The radiant heat flux (R) between the neonate's skin and its surroundings is described by Stephan-Boltzmann's law:

$$
\mathrm{R}=\mathrm{h}_{\mathrm{r}}\left[\left(\overline{\mathrm{T}}_{\mathrm{sk}}+273\right)^{4}-\left(\overline{\mathrm{T}}_{\mathrm{r}}+273\right)^{4}\right] \mathrm{F}_{\mathrm{cl}}
$$

where $h_{r}$ is the radiant heat transfer coefficient, $\bar{T}_{r}$ is the mean radiant temperature of the surrounding radiant surfaces, $\overline{\mathrm{T}}_{\mathrm{sk}}$ is the mean skin temperature, and $\mathrm{F}_{\mathrm{cl}}$ is the reduction factor due to due to the diaper (together with a bonnet and/or a transparent plastic bag, if present). For premature infant clothing insulation consisted of a diaper in combination with a bonnet covering the scalp and / or a transparent plastic bag covering the torso and the limbs.

The heat loss by transepidermal water loss (E) can be formulated as:

$$
\mathrm{E}=\mathrm{h}_{\mathrm{e}} \omega\left(\mathrm{P}_{\mathrm{sH} 20}-\mathrm{P}_{\mathrm{aH} 20}\right) \mathrm{F}_{\mathrm{pcl}}
$$

where $h_{e}$ is the evaporative heat loss coefficient, $\omega$ is the fraction of skin area that is completely wet, $\mathrm{P}_{\mathrm{sH} 20}-\mathrm{P}_{\mathrm{aH} 20}$ is the water vapor partial pressure difference between the skin $\left(\mathrm{P}_{\mathrm{sH} 2 \mathrm{O}}\right)$ and the air, $\left(\mathrm{P}_{\mathrm{aH} 2 \mathrm{O}}\right)$, and $\mathrm{F}_{\mathrm{pcl}}$ is the reduction factor for water vapor transfer due to the diaper (together with a bonnet and/or a transparent plastic bag, if present). To take account of the fact that extremely-low-birth-weight neonates have a very thin skin (enhancing transepidermal water loss), $\omega$ varied from 0.412 on the first day of life to 0.08 after 10 days of life [13].

Evaporative heat loss (due to breathing) can be expressed as:

$$
\text { Eresp }=\mathrm{V}_{\mathrm{E}} \delta\left(\mathrm{M}_{\mathrm{e}}-\mathrm{M}_{\mathrm{i}}\right)
$$

where $V_{E}$ is the pulmonary ventilation rate, $\delta$ is the latent heat of water vaporization, and $M_{e}-M_{i}$ is the difference in water content between expired air $(\mathrm{Me})$ and inspired air (Mi). When a neonate is receiving ventilatory support or oxygen support, $\mathrm{M}_{\mathrm{i}}$ is the water content of the supplied air or oxygen.

The heat transfer from the skin surface to the moving air in the incubator $(C)$ is quantified as:

$$
\mathrm{C}=\mathrm{h}_{\mathrm{c}}\left(\mathrm{T}_{\mathrm{a}}-\overline{\mathrm{T}}_{\mathrm{sk}}\right) \mathrm{F}_{\mathrm{cl}}
$$

where $h_{c}$ is the convective heat transfer coefficient, and $T_{a}$ is the incubator air temperature. Natural convection (also termed "free convection") is driven by the temperature difference between the air and 
the skin. Forced convection occurs at air speeds of more than $0.2 \mathrm{~m} / \mathrm{s}$. Mixed-mode convection occurs between these two limits.

The convective heat loss through the respiratory tract is defined as:

$$
\text { Cresp }=V_{E} C p\left(T_{e}-T_{i}\right)
$$

where $\mathrm{Cp}$ is the heat capacity of the air, and $\mathrm{T}_{e}-\mathrm{Ti}$ is the temperature difference between expired air and inspired air. In a closed incubator, $\mathrm{T}_{\mathrm{i}}=\mathrm{T}_{\mathrm{a}}$. When a neonate is receiving ventilatory support or oxygen support, $\mathrm{T}_{\mathrm{i}}$ is the temperature of the supplied air or oxygen.

The heat conducted from the skin to the mattress $(K)$ is calculated using Fourier's law:

$$
\mathrm{K}=\mathrm{h}_{\mathrm{K}}\left(\mathrm{T}_{\mathrm{m}}-\overline{\mathrm{T}}_{\mathrm{sk}}\right)
$$

where $h_{K}$ is the conductive heat transfer coefficient, and $T_{m}$ is the temperature of the mattress surface.

Lastly, the conventional heat balance equation for heat stored in the body (S) can be written as:

$$
\mathrm{S}=\mathrm{M} \pm \mathrm{R}-\mathrm{E}-\text { Eresp } \pm \mathrm{C} \pm \text { Cresp } \pm \mathrm{K}
$$

Metabolic heat production was assessed as a function of post-natal age, as recommended by Chessex et al. for very low birth weight neonates [14].

When the heat storage is nil, the body reaches a thermal equilibrium with its surroundings, and the neonate's thermal environment is optimal.

An example of the set of software variables used to calculate the thermal environment in a closed incubator is shown in Figure 2:

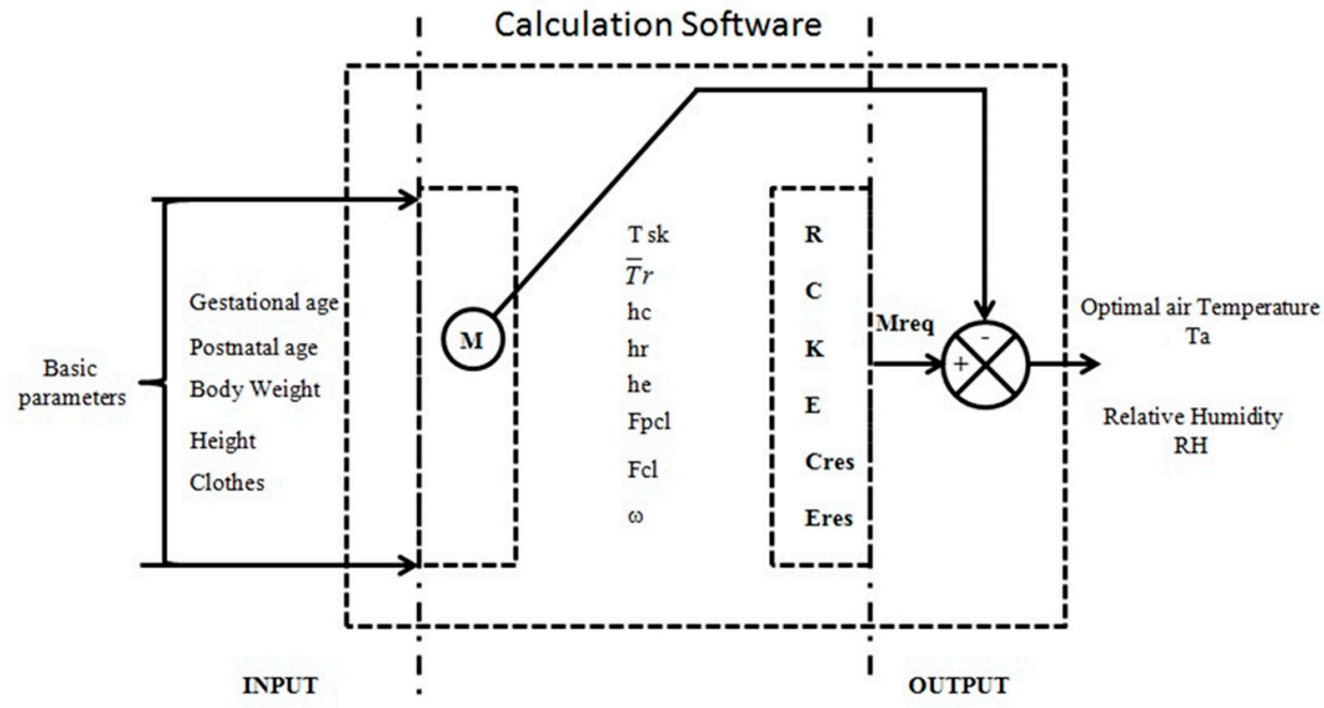

Figure 2. Variables (inputs) used by software to assess ambient conditions in a closed incubator (output), on the basis of the mathematical equations given above.

The basic software settings (input parameters) were provided by the nursing staff. Output variables were calculated from the difference between the metabolism (Mreq) required to achieve thermal equilibrium and the calculated metabolism $(\mathrm{M})(\mathrm{S}=0)$. The infant's degree of maturity was reflected by the body weight and the gestational and postnatal ages.

To validate a model's predictive ability, the sum of the heat exchanges is sometimes compared with the metabolic heat production measured by indirect respiratory calorimetry. This standard method consists in measuring energy expenditure from $\mathrm{O}_{2}$ consumption and $\mathrm{CO}_{2}$ production by neonates nursed at thermal neutrality $(S=0)$ in closed incubators [15,16]. Adams et al. [15] reported 
that the difference between the two methods was 1.3\%, whereas Museux et al. [16] found a value of $3.3 \%$ - corresponding to a daily error of less than $5.3 \mathrm{~g}$ in the prediction of body growth. These differences with the standard method were not significant, and the authors concluded that models based on the body heat balance equation provide reliable information for calculating the energy expenditure of an individual neonate.

\section{Limitations of Mathematical Models}

Although mathematical models constitute a convenient means of assessing various heat-stress scenarios and then making recommendations, they are not easily applicable to the complicated thermal environment inside an incubator. The mathematical equations that describe body heat exchanges cannot be easily calculated from known physical laws, and are based on various empirical determinations. The problem is to find appropriate values for the parameters when a model is used for developing organisms (as opposed to adults) because the relative surface areas of the different body segments vary with body mass.

The assumptions used to determine values of $\mathrm{h}_{\mathrm{c}}$ from theory (for standing adults, and restricted to either natural or forced convection) lead to errors. For example, neonates have larger convective heat transfer coefficients than adults. Air speed in the incubator (which determines whether convection is free or forced or mixed) is also relevant. The results of three-dimensional computational fluid mechanical studies of air flow in incubators $[17,18]$ have shown that air flow is not uniform; this non-uniformity, therefore, interferes with the determination of convective and evaporative heat transfer coefficients. The presence of eddies (i.e., small air vortices at the neonate's skin surface) leads to mixed-mode convection. Under these conditions, the equations used to calculate the combined heat transfer coefficient are not satisfactory.

As mentioned above, clothing reduces radiant, convective and evaporative heat exchanges. There are no quantitative guidelines on the use of clothing for neonates. In the mathematical equations, the values of the reduction factors $\mathrm{F}_{\mathrm{cl}}$ and $\mathrm{F}_{\mathrm{pcl}}$ have been assessed with reference to the ISO 9920:1995 (F) standard [19] for adults by taking account of the percentage of the skin surface area covered by the fabric and the latter's thickness.

As also mentioned above, the marked skin temperature differences between body segments mean that the conventional method for calculating $\overline{\mathrm{T}}_{\mathrm{sk}}$ (i.e., spot measurements of several local skin temperatures) is not entirely suitable. Given that each body site has a specific weighting factor (i.e., the site's surface area relative to the total body surface area, which varies with body mass), the equations for calculating $\overline{\mathrm{T}}_{\mathrm{sk}}$ should differ from one neonate to another.

None of the incubators currently on the market feature a device for measuring $\overline{\mathrm{T}}_{\mathrm{r}}$; hence, this parameter warrants more detailed investigation with regard to the geometric aspects of a neonate's posture, and the neonate's location in the incubator. $\bar{T}_{\mathrm{r}}$ is unlikely to be equal to the air temperature [20] or to a mean value calculated from the temperatures of the incubator inner walls and the mattress surface [15] or from the incubator and room air temperatures [21]. As reported by Ultman et al. [22] for a single-walled incubator, $\overline{\mathrm{T}}_{\mathrm{r}}$ can be 4.0 to $5.5^{\circ} \mathrm{C}$ lower than the incubator air temperature. When studying a single-wall incubator with a double-wall roof panel (the Satis ${ }^{+}$from Médipréma, Tauxigny, France), Décima et al. [23] found a difference of $2.7^{\circ} \mathrm{C}$; this is similar to the value of $3.1^{\circ} \mathrm{C}$ determined by Wheldon [21] for the Vickers 79 closed incubator (Vickers Medical, UK) and the value of $3.5^{\circ} \mathrm{C}$ determined by Sinclair [24] for the Isolette closed incubator, Air-Shields Vickers, UK.

$\overline{\mathrm{T}}_{\mathrm{r}}$ can be measured using (i) matt-black copper globe thermometers, (ii) thermopile transducers in the mattress, (iii) a radiometer with two heat flow sensors, and (iv) a copper ellipsoid heated to simulate the neonate's convective and radiant heat losses. Each of these methods has several major disadvantages, since none accounts for the effect of an infant's body contours on radiant heat exchanges. The various apparatuses do not have the same radiant view factor as a neonate. Moreover, the globe thermometers and the heated copper ellipsoid have slow responses, which would mask any dynamic changes in the incubator. 
Thus, the theoretical mathematical models used to describe neonate's thermal responses are only valid in a homogeneous thermal environment; they do not take sufficient account of several aspects of the thermal heterogeneity surrounding the neonate.

\section{How to Solve (at Least in Part) These Problems}

A lack of confidence in mathematical models has prompted attempts to assess and simplify the parameters governing heat fluxes between the neonate and the environment. In a thermally non-uniform environment (such as that encountered in a incubator) with radiant asymmetries, temperature gradients and turbulent air flow, the use of skin-temperature-controlled articulated thermal mannequins can bridge the gap between the simplification of scientific theory and the complexities of real nursing care.

Surface temperatures are measured by sensors imbedded in the mannequin's solid copper structure. Using separate resistance wires, each segment is heated to a set-point temperature corresponding to that recorded in neonates.

Mannequins have previously been used as replicas of term neonates [17,21,25]. Although these models give relevant information, the physical form is often over simplified (e.g., linked, smooth cylinders), the different body segments are not always thermally independent, and skin wetting is not simulated. Hence, this lack of similarity to a real neonate which can introduce errors into the calculation of heat transfers. To solve these problems, Elabbassi et al. designed an anthropomorphic, multisegment thermal mannequin representing a small-for-gestational age neonate (Figure 3) [18,26]. Each body segment can act independently from the others, so as to simulate heterogeneity in skin temperatures and heat exchanges. The copper mannequin is painted with a thin layer of matt black paint, so that its surface emissivity is similar to that of human skin. Electrical wires placed inside each of the mannequin's members can be used to simulate the regional skin temperature heterogeneity (Figure $3 b$ ) recorded (using infrared thermography) for real neonates. In a study of a thermal mannequin simulating a neonate with very low birth weight, Belghazi et al. [27] also included a sweating feature. Firstly, the mannequin's surface was covered with a black cotton stocking, in order to simulate water evaporation from the surface. Secondly, a pump system was used to supply water to each segment heated to a given set-point temperature by individual resistance wires. Hence, the level of skin wetting could be controlled as a function of the environmental conditions, in order to provide information on evaporative heat transfers for each body segment.

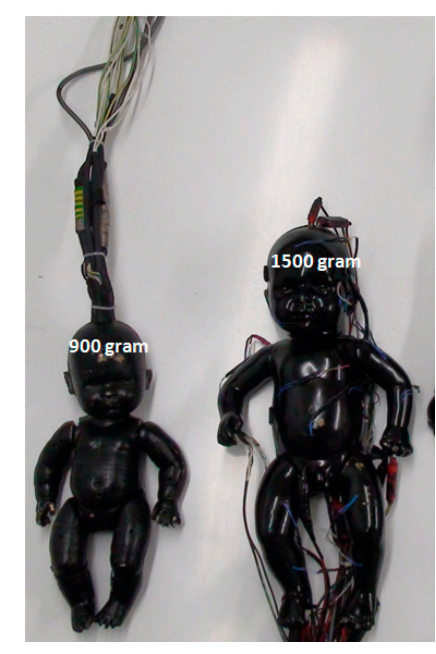

(a)

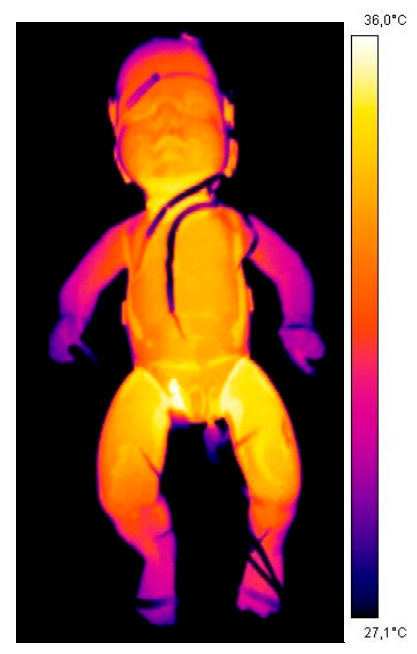

(b)

Figure 3. (a) Anthropomorphic, multisegment thermal mannequins representing premature neonates with simulated birth weights of $900 \mathrm{~g}$ (left), $1500 \mathrm{~g}$ (right); (b) the mannequin's regional skin temperatures (recorded using infrared thermography) simulate the heterogeneity observed in neonates nursed in closed incubators. 
Mannequins can be used to experimentally determine $\bar{T}_{\mathrm{r}}$ and several factors related to heat transfer coefficients with less uncertainty. For example, Figure 4 compares the $\left(\mathrm{T}_{\text {inc }}\right)$ calculated from a standard procedure (in which $\overline{\mathrm{T}}_{\mathrm{r}}$ is assessed with a standard globe thermometer) with that obtained from experiments on the anthropomorphic, multisegment thermal mannequin [23]. The data showed that the standard procedure underestimated $\mathrm{T}_{\text {inc }}$, which increased the risk of body cooling. Differences ranging between 0.92 and $1.56{ }^{\circ} \mathrm{C}$ are clinically relevant if one considers that the range of $T_{\text {inc }}$ for very premature neonates is narrow (perhaps even a single temperature point [28].
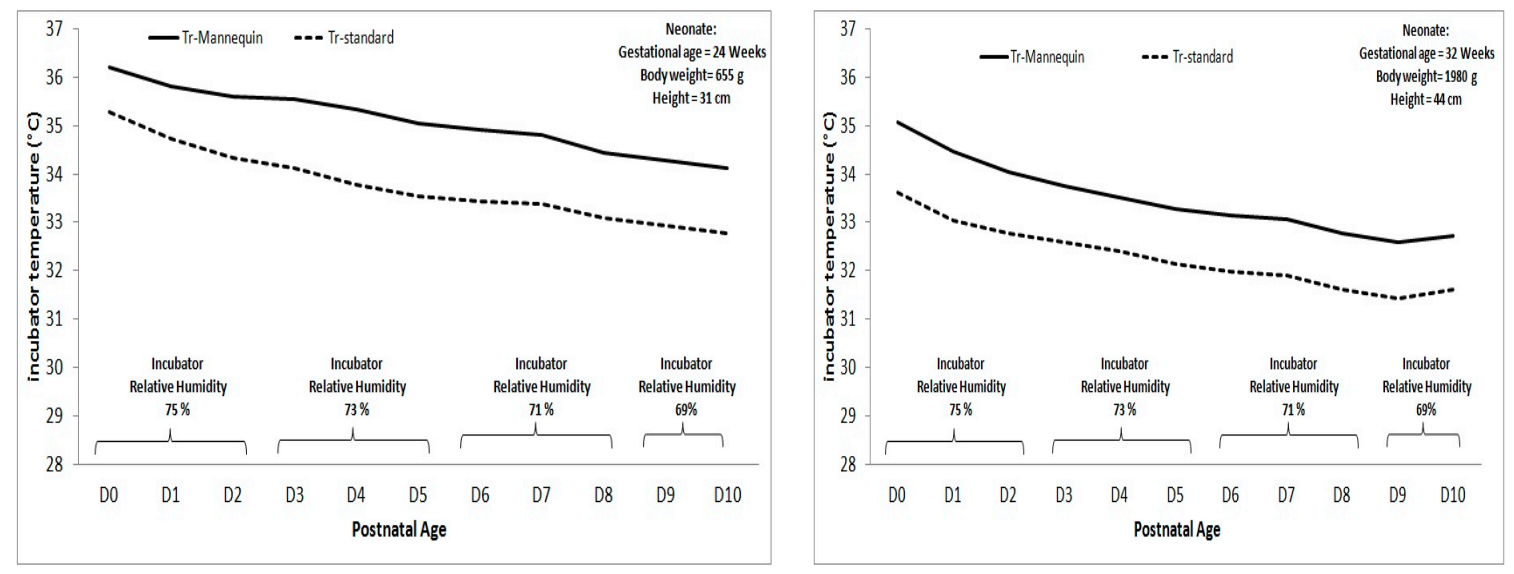

Figure 4. Optimal incubator air temperatures $\left(\mathrm{T}_{\mathrm{inc}}\right)$ in a mathematical model as a function of postnatal age for two neonates (body mass: $655 \mathrm{~g}$ and $1980 \mathrm{~g}$, respectively). $\mathrm{T}_{\text {inc }}$ was calculated using the mean radiant temperature measured with a standard black-globe thermometer $\left(\bar{T}_{r}\right.$-standard, dotted line $)$ or using a thermal mannequin ( $\bar{T}_{\mathrm{r}}-$ mannequin, full line). The relative humidity levels are those commonly recommended by Helder et al., (2008) [29] in the incubator for these populations of neonates.

\section{Applications and Research Perspectives}

In clinical situations, the models can thus be used easily to define the optimal temperature at which a neonate should be nursed [30-32] for the optimization of body growth and survival. The models can also be used to make recommendations for avoiding hypothermia or hyperthermia. Lastly, the models can calculate body heat storage in various hyperthermia-promoting scenarios and can estimate the likely time until death. Thus, Jardine [20] showed that the effect of increased blanket thickness is always less than that caused by reduced skin exposure, and that hyperthermia only develops when the head and neck are entirely covered. Bolton et al. [32] defined the highest tolerable air temperature for a given set of clothes and/or covers. Agourram et al. [33] showed that a combination of a bonnet and a polyethylene bag (a commonly used method for preventing evaporative heat loss [3,34] can result in hyperthermia but only when metabolic heat production rises while the skin temperature falls, as sometimes happens in newborns with fever [35]. Agourram et al. also reported on the time required to reach lethal thresholds in various clinical situations [33]. All the models show that when an infant is heavily dressed, additionally covering the head with a bonnet can trigger lethal hyperthermia. The heat loss is lower when the head in is a face-down position or is covered by bedding. All the studies emphasize that a neonate with fever should be less extensively wrapped, rather than more extensively.

The heat exchanges for a thermal mannequin representing a small-for-gestational-age premature infant (weighing $900 \mathrm{~g}$ or $1500 \mathrm{~g}$; see Figure 3) were quantified in a closed incubator (the Satis ${ }^{+}$ from Médipréma, Tauxigny, France) before and after phototherapy (Lullaby LED Phototherapy System, GE Medical Systems, Laurel, MD, USA). The device was located $35 \mathrm{~cm}$ above the mannequin, as recommended by the manufacturer. The incorporation of preliminary data into the predictive model $[30,31]$ showed that in order to achieve an optimal thermal environment during phototherapy, the mean \pm standard deviation (SD) incubator air temperature can be decreased by $0.68 \pm 0.15$ (for the 
$900 \mathrm{~g}$ neonate) and $0.72 \pm 0.07^{\circ} \mathrm{C}$ (for the $1500 \mathrm{~g}$ neonate) in the first days of life. These preliminary data must now be confirmed in clinical trials.

Since cold stress on admission increases the risk of hypothermia in the first $3 \mathrm{~h}$ of life [36], broader application of the models will need to improve the thermal performance of transport incubators via the inclusion of the outside air temperature $\left(\mathrm{T}_{\text {out }}\right)$; the cool incubator wall enhances radiant heat loss when the neonate is transported in a cold environment. Although the influence of radiant heat loss can be an estimation using Wheldon's equation for the mean radiant temperature $\mathrm{T}_{\mathrm{r}}$ (based on the incubator's $\mathrm{T}_{\mathrm{a}}$ and $\mathrm{T}_{\text {out }}$ ), this approach has yet to be validated in a premature neonate [23]. Wheldon used a mannequin (simulating a newborn of $3300 \mathrm{~g}$, with a simple geometric shape and a uniform surface temperature across all body segments), which was exposed in a closed incubator at room air temperatures of between 20 and $30^{\circ} \mathrm{C}$. In our opinion, it is preferable to (i) make measurements at the lower outside air temperatures encountered during transport and (ii) use anthropomorphic thermal mannequins that simulate premature, low-birth-weight neonates.

Inter-infant differences in thermoregulatory control, metabolic heat production, behavioural and vasomotor responses, and skin evaporative heat loss will have to be incorporated in these models. One cannot rule out changes in the neonate's ability to dissipate heat (i.e., the model's performance as a function of skin characteristics, hydration levels, feeding, nursing care, and sleep. In the future, it may be possible to complement mathematical models with an active cybernetic system for predicting thermoregulatory responses (such as shivering, changes in the peripheral vasomotor tone, metabolic heat production, and skin water loss) by incorporating heat capacities and energy fluxes from the different tissues (i.e., internal organs, adipose tissue, muscle, and skin sites).

Future research should seek to quantify the strength of the relationship between heat transfer coefficients on one hand and body size and posture on the other. With the exception of Wheldon's study [21], there are few published data on the effect of the neonate's body position on heat exchanges inside the incubator. By studying a mannequin representing a newborn with a body mass of $3300 \mathrm{~g}$, Wheldon showed that the heat transfer coefficient $h_{c}$ was $4.00 \mathrm{~W} / \mathrm{m}^{2} /{ }^{\circ} \mathrm{C}$ in the foetal position, $3.90 \mathrm{in}$ the relaxed position, and 4.91 in the spread-eagle position; the radiant heat transfer coefficient $h_{r}$ was $3.10,3.70$ and $4.90 \mathrm{~W} / \mathrm{m}^{2} /{ }^{\circ} \mathrm{C}$, respectively. Body size modifies the skin surface area to body volume ratio; the greater this ratio, the greater the body's heat losses to the environment. Elabbassi et al. [37] compared dry heat losses from two mannequins simulating infants weighing $900 \mathrm{~g}$ and $1800 \mathrm{~g}$, respectively; the heat losses were $20.4 \%$ greater for the smaller mannequin.

Further studies could usefully analyse the local effects of non-uniform thermal environments and air movement directions, such as those encountered in the incubator. A segment-by-segment approach requires the consideration of interregional skin temperature differences between the body sites, reflecting both the local vascular responsiveness and the heat exchanges with the surroundings. A detailed model can take account of heat transfer coefficients for individual body segments. Using a skin-temperature-controlled adult mannequin, De Dear et al. [38] found that the values of $h_{c}$ were higher for peripheral body segments than for central segments. The difference was as much as $60 \%$ for lower air speeds, highlighting the errors induced by applying the whole-body value of $h_{c}$ to a non-uniform thermal environment. De Dear et al. also reported that air flow direction was a relevant parameter when calculating the heat balance for body segments such as feet and lower legs, where convective heat losses are particularly high. Interestingly, Bolton et al. [32] assessed the risks of hyperthermia and hypothermia in neonates by calculating the heat exchanges for 11 body segments. However, as acknowledged by the researchers themselves, this theoretical model of heat transfers has yet to be validated, especially for newborns of various body sizes.

The relevance of the thermal instability potentially produced by care procedures has yet to be assessed. The degree of instability is likely to depend on the frequency, type and duration of care. However, the lack of standardization of care procedures [39] and the use of fixed parameters (such as heat exchange coefficients calculated for closed incubators) in today's mathematical models prevents researchers from studying the dynamic behavior of intermittently open neonate-incubator systems. 


\section{Conclusions}

Despite uncertainties related to the parameters included in heat-transfer equations, mathematical models help to predict the occurrence of thermal stress and the time before dangerous thresholds are reached during complex nursing care. The application of mathematical models not only assists caregivers with the thermal management of neonates but can also facilitate dynamic thermal control when heat losses change suddenly (invasive care procedures, intubation, incubator air temperature overshoots and undershoots, etc.). In these situations, a mathematical model can predict the relative contributions of the different heat exchanges so that selective action can be taken to maintain body homeothermia.

Author Contributions: All the authors actively contributed to the research described herein. S.D. designed the different models and the software, J.-P.L. helped to design the software, implemented the various mathematical expressions, and formulated the hypotheses related to the hospital care of premature newborns. F.C.Y., E.D. and P.T. worked on the experimental design, data collection and data processing. P.T. was also responsible for clinical trials.

Funding: This research received no external funding.

Conflicts of Interest: The authors declare no conflict of interest.

\section{References}

1. Foster, K.G.; Hey, E.N.; Katz, G. The response of the sweat glands of the new-born baby to thermal stimuli and to intradermal acetylcholine. J. Physiol. 1969, 203, 13-29. [CrossRef] [PubMed]

2. Kroth, J.; Weidlich, K.; Hiedl, S.; Nussbaum, C.; Christ, F.; Genzel-Boroviczény, O.; Genzel-Borovicz, O. Functional Vessel Density in the First Month of Life in Preterm Neonates. Pediatr. Res. 2008, 64, 567-571. [CrossRef]

3. Knobel, R.B.; Holditch-Davis, D.; Schwartz, T.A.; Wimmer, J.E.; Wimmer, J.E., Jr. Extremely low birth weight preterm infants lack vasomotor response in relationship to cold body temperatures at birth. J. Perinatol. 2009, 29, 814-821. [CrossRef] [PubMed]

4. Department of Reproductive Health and Research. World Health Organisation Thermal Protection of the Newborn: A Practical Guide; Department of Reproductive Health and Research: Geneva, Switzerland, 1997.

5. Laptook, A.R.; Salhab, W.; Bhaskar, B.; Neonatal Research Network. Admission Temperature of Low Birth Weight Infants: Predictors and Associated Morbidities. Pediatrics 2007, 119, e643-e649. [CrossRef]

6. Bredemeyer, S.; Reid, S.; Wallace, M. Thermal management for premature births. J. Adv. Nurs. 2005, 52, $482-489$. [CrossRef]

7. Baumgart, S.; Engle, W.D.; Fox, W.W.; Polin, R.A. Effect of heat shielding on convective and evaporative heat losses and on radiant heat transfer in the premature infant. J. Pediatr. 1981, 99, 948-956. [CrossRef]

8. Soll, R.F. Heat loss prevention in neonates. J. Perinatol. 2008, 28, S57-S59. [CrossRef]

9. Sofer, S.; Phillip, M. Hemorrhagic Shock and Encephalopathy Syndrome. AJDC 1986, 140, $1252-1254$. [CrossRef]

10. Frank, J.; Brown, S. Thermometers and rectal perforations in the neonate. Arch. Dis. Child. 1978, 53, 824-825. [CrossRef]

11. Lenzi, P.; Libert, J.; Franzini, C.; Cianci, T.; Guidalotti, P. Short-term thermoregulatory adjustments involving opposite regional temperature changes. J. Therm. Biol. 1986, 11, 151-156. [CrossRef]

12. Cross, K.; Stratton, D. Aural temperature of the newborn infant. Lancet 1974, 304, 1179-1180. [CrossRef]

13. Hammarlund, K.; Sedin, G.; Strömberg, B. Transepidermal Water Loss in Newborn Infants. Acta Paediatr. 1982, 71, 369-374. [CrossRef]

14. Chessex, P.; Reichman, B.L.; Verellen, G.J.; Putet, G.; Smith, J.M.; Heim, T.; Swyer, P.R. Influence of postnatal age, energy intake, and weight gain on energy metabolism in the very low-birth-weight infant. J. Pediatr. 1981, 99, 761-766. [CrossRef]

15. Adams, A.K.; Nelson, R.A.; Bell, E.F.; Egoavil, C.A. Use of infrared thermographic calorimetry to determine energy expenditure in preterm infants. Am. J. Clin. Nutr. 2000, 71, 969-977. [CrossRef] 
16. Museux, N.; Cardot, V.; Bach, V.; Delanaud, S.; Degrugilliers, L.; Agourram, B.; Elabbassi, E.B.; Libert, J.-P. A reproducible means of assessing the metabolic heat status of preterm neonates. Med. Phys. 2008, 35, 89-100. [CrossRef]

17. Konecny, E.; Frankenberger, R.T.; Bussmann, O.; Nahm, W. Modell zur Simulation der Wärmeabgabe von Frühgeborenen. Simulation Model of Heat Loss in Preterm Infants. Biomed. Tech. Eng. 1998, 43, 137-143.

18. Elabbassi, E.B.; Bach, V.; Makki, M.; Delanaud, S.; Telliez, F.; Léké, A.; Libert, J.-P. Assessment of dry heat exchanges in newborns: Influence of body position and clothing in SIDS. J. Appl. Physiol. 2001, 91, 51-56. [CrossRef]

19. ISO 9920 (1995). Ergonomie des ambiances thermiques: Détermination de l'isolement vestimentaire et de la résistance à l'évaporation d'une tenue vestimentaire. AFNOR 2002, 313-372, ISBN (tome2):2-12-213562-X.

20. Jardine, D.S. A mathematical model of life-threatening hyperthermia during infancy. J. Appl. Physiol. 1992, 73, 329-339. [CrossRef]

21. Wheldon, A.E. Energy balance in the newborn baby: Use of a manikin to estimate radiant and convective heat loss. Phys. Med. Biol. 1982, 27, 285-296. [CrossRef]

22. Ultman, J.S.; Berman, S.; Kirlin, P.; Vreslovic, J.M.; Baer, C.B.; Marks, K.H. Electrically heated simulator for relative evaluation of alternative infant incubator environments. Med. Instrum. 1988, 22, 33-38.

23. Décima, P.; Stéphan-Blanchard, E.; Pelletier, A.; Ghyselen, L.; Delanaud, S.; Dégrugilliers, L.; Telliez, F.; Bach, V.; Libert, J.-P. Assessment of radiant temperature in a closed incubator. Eur. J. Appl. Physiol. 2012, 112, 2957-2968. [CrossRef]

24. Sinclair, A. The measurement of radiant temperature in neonatal thermal environments. Biomed. Instrum. Technol. 1992, 26, 400-407.

25. Sarman, I.; Bolin, D.; Holmér, I.; Tunell, R. Assessment of Thermal Conditions in Neonatal Care: Use of a Manikin of Premature Baby Size. Am. J. Perinatol. 1992, 9, 239-246. [CrossRef]

26. Elabbassi, E.B.; Chardon, K.; Telliez, F.; Bach, V.; Libert, J.-P. Influence of head position on thermal stress in newborns: Simulation using a thermal mannequin. J. Appl. Physiol. 2002, 93, 1275-1279. [CrossRef]

27. Belghazi, K.; Tourneux, P.; Elabbassi, E.B.; Ghyselen, L.; Delanaud, S.; Libert, J.-P. Effect of posture on the thermal efficiency of a plastic bag wrapping in neonate: Assessment using a thermal "sweating" mannequin. Med. Phys. 2006, 33, 637-644. [CrossRef]

28. Wheldon, A.E.; Hull, D. Incubation of very immature infants. Arch. Dis. Child. 1983, 58, 504-508. [CrossRef]

29. Helder, O.K.; Mulder, P.G.H.; Van Goudoever, J.B. Computer-Generated Versus Nurse-Determined Strategy for Incubator Humidity and Time to Regain Birthweight. J. Obstet. Gynecol. Neonatal Nurs. 2008, 37, $255-261$. [CrossRef]

30. Lyon, A.; Oxley, C. HeatBalance, a computer program to determine optimum incubator air temperature and humidity. A comparison against nurse settings for infants less than 29 weeks gestation. Early Hum. Dev. 2001, 62, 33-41. [CrossRef]

31. Décima, P.; Dégrugilliers, L.; Delanaud, S.; Stéphan-Blanchard, E.; Vanhée, J.-L.; Libert, J.-P. Conception d'un logiciel de calcul de la thermoneutralité dans les incubateurs fermés pour nouveau-nés prématurés (projet Pretherm ${ }^{\circledR}$ ). IRBM 2012, 33, 48-54. [CrossRef]

32. Delanaud, S.; Decima, P.; Pelletier, A.; Libert, J.-P.; Durand, E.; Stephan-Blanchard, E.; Bach, V.; Tourneux, P. Thermal management in closed incubators: New software for assessing the impact of humidity on the optimal incubator air temperature. Med. Eng. Phys. 2017, 46, 89-95. [CrossRef]

33. Bolton, D.P.; Nelson, E.A.; Taylor, B.J.; Weatherall, I.L. Thermal balance in infants. J. Appl. Physiol. 1996, 80, 2234-2242. [CrossRef]

34. Agourram, B.; Bach, V.; Tourneux, P.; Krim, G.; Delanaud, S.; Libert, J.-P. Why wrapping premature neonates to prevent hypothermia can predispose to overheating. J. Appl. Physiol. 2010, 108, 1674-1681. [CrossRef]

35. Vohra, S.; Roberts, R.S.; Zhang, B.; Janes, M.; Schmidt, B. Heat Loss Prevention (HeLP) in the delivery room: A randomized controlled trial of polyethylene occlusive skin wrapping in very preterm infants. J. Pediatr. 2004, 145, 750-753. [CrossRef]

36. Berardi, A.; Lugli, L.; Baronciani, D.; Creti, R.; Rossi, K.; Ciccia, M.; Gambini, L.; Mariani, S.; Papa, I.; Serra, L.; et al. Group B Streptococcal Infections in a Northern Region of Italy. PEDIATRICS 2007, 120, e487-e493. [CrossRef] 
37. Mank, A.; van Zanten, H.A.; Meyer, M.P.; Pauws, S.; Lopriore, E.; Te Pas, A.B. Hypothermia in Preterm Infants in the First Hours after Birth: Occurrence, Course and Risk Factors. PLoS ONE 2016, 11, e0164817. [CrossRef]

38. Elabbassi, E.B.; Belghazi, K.; Libert, J.-P. Dry heat loss in incubator: Comparison of two premature newborn sized manikins. Eur. J. Appl. Physiol. 2004, 92, 679-682. [CrossRef]

39. De Dear, R.J.; Arens, E.; Hui, Z.; Oguro, M.C. Convective and radiative heat transfer coefficients for individual human body segments. Int. J. Biometeorol. 1997, 40, 141-156. [CrossRef]

(C) 2019 by the authors. Licensee MDPI, Basel, Switzerland. This article is an open access article distributed under the terms and conditions of the Creative Commons Attribution (CC BY) license (http://creativecommons.org/licenses/by/4.0/). 